\title{
Negotiating Tensions on the Front Line: Circuits of Accountability and Self- governance in Institutional Care of Adults with Intellectual Disability
}

\author{
Khalilah Robinson Johnson (DD \\ University of North Carolina at Chapel Hill, USA
}

\section{Nancy Bagatell}

University of North Carolina at Chapel Hill, USA

\begin{abstract}
This article explores how circuits of accountability impact front-line service work in an intermediate care facility for individuals with intellectual disability (ICF/IID). Institutional ethnography as a theory and methodology guided the data collection and analysis processes. Participant observation and interviews were completed, and text work was employed to make visible the ways staff enacted what they believed to be their roles and responsibilities. Results indicated the service criteria established by regulatory agencies were interpreted and executed in ways that negatively influenced staff's moral care to residents and restricted their ability to self-govern and utilize their experiential knowledge. Additionally, the institution's circuits of accountability reflected ideals of front-line work that were inconsistent with staff's perception of their responsibilities. These findings have implications for management and implementation of direct care in ICFs/IID and underscore the importance of aligning moral care and self-governance to front-line service work.
\end{abstract}

\section{Keywords}

accountability circuit, front-line service work, institutional ethnography, intellectual disability, self-governance

\section{Corresponding author:}

Khalilah Robinson Johnson, Division of Occupational Science and Occupational Therapy, University of North Carolina at Chapel Hill, Campus Box \# 7I22, Bondurant Hall, Chapel Hill, NC 27599, USA.

Email: Khalilah_Johnson@med.unc.edu 
. . . a deeper understanding of service work is possible if the worker-consumer interaction is conveyed of as part of the social structure that shapes it, namely the employment relationship.

Bélanger and Edwards (2013: 434).

Adults with intellectual disability (ID) in institutional settings rely on front-line service workers throughout their day. Front-line service work refers to the employment activities in direct contact with service recipients, and front-line workers are personnel who occupy a subordinate position in the employment relationship (Bélanger and Edwards, 2013; Lopez, 2010). Scholarship on front-line work in institutional settings for adults with ID in the United States has been limited to understanding and chronicling unskilled custodial care, abuse and neglect, consumer exploitation, deinstitutionalization, and care expenditures (Braddock et al., 2017; Wehmeyer, 2013). Contemporary research on adults with ID has shifted from institutionalization to acknowledging the impact of stigma on social engagement, human and disability rights, self-determination, and habilitative training necessary for community transition to name a few (Johnson and Bagatell, 2017; Nielsen, 2012). Despite these shifts in foci, little has been added to the knowledgebase on the nature of work and consumer care in contemporary institutions commonly known as intermediate care facilities for individuals with intellectual disability (ICFs/IID).

This article calls attention to the implementation and challenges of front-line work for staff members in an ICF/IID. These front-line workers, referred to as habilitation technicians, work within institutional complexes that they must encounter, enact, challenge, and sometimes reject (Grace et al., 2014). These institutional complexes include, but are not limited to, the guiding principles of the institution and regulations that define and coordinate interactions between habilitation technicians and the execution of care to adults with ID. Habilitation technicians are expected to read and decipher these regulations, which require they become knowledgeable readers of texts, make sense of their structural and linguistic complexities, and apply that knowledge in novel yet practical ways. This process is intensive, highly routinized and conditioned by relations that allow for careful oversight of habilitation technicians' work (Johnson and Bagatell, 2017). Various forms of accountability circuits fall within these complexes and are officially represented through the material documentation and technologies habilitation technicians engage to fulfil that accountability (DeVault et al., 2014; Griffith and Smith, 2014). Their participation in these complexes creates tensions in front-line service work.

An accountability circuit is a form of coordination that brings front-line work into alignment with institutional objectives through the activation of texts. In general, its purpose is to 'bring together people who have - or at least appear to have - shared interests' in certain outcomes in an institutional setting (Grace et al., 2014: 254). Texts impose specific expectations for acting or being, and front-line workers account for those ways of acting and being largely through daily charting of completed work tasks. Griffith and Smith (2014) theorized that front-line workers' self-governance is also drawn into accountability circuits through their documentation. Therefore, workers' participation in these circuits is immediately aligned with prescribed reporting requirements and ways of performing work tasks. The mere act of documenting their work and being assessed by 
managers directly shapes the actual doing and representation of front-line work (DeVault et al., 2014; Wagner, 2014). Sørensen and Triantafillou (2016) also agreed that the desires of those who execute work, on the front line or otherwise, are commensurate with institutional objectives. However, what is not accounted for are actions or duties that are not explicitly defined in texts such as habilitation technicians' ability to make decisions and adaptations in order to individualize care, as well as their values and moral obligations to residents in ICFs/IID.

Juxtaposed with accountability circuits is the notion of self-governance, which refers to the ability to exercise power and self-determined decision-making without intervention from an outside authority (Sørensen and Triantafillou, 2016). Habilitation technicians' selfgovernance, as discussed below, is not divorced from institutional oversight; rather, their self-governance is mediated through accountability circuits by enacting the personnel and regulatory texts that specify roles, responsibilities or procedures and their associated documentation. These texts are bound by state and national mandates that organize front-line work in ICFs/IID in ways that can come into conflict with the habilitation technicians' sense of obligation to the residents. This moral obligation - the duty or responsibility a person feels compelled to perform because of personal values and beliefs about right and wrong (Skorupski, 2010) - is different from text-based forms of accountability. The habilitation technicians are bound to accountability circuits through texts and bound to the residents by their personal commitments and values; this moral obligation to residents compels them to prioritize moral or ethical care (Capri and Swartz, 2018) - a form of caregiving habilitation technicians believe to be client-centred and to bring meaning to residents' lives.

The act of engaging in moral care 'encourages dignity, promotes well-being, fosters autonomy and confidence, and validates adult status' (Capri and Swartz, 2018: 289); yet, data presented here illustrate that moral care is not aligned with or valued within the textual complexes organizing front-line work. The absence of work that brings meaning to the lives of residents by elevating the monotony of day-to-day living implies that habilitation technicians are not able to exercise self-governance. Habilitation technicians' labour, as prescribed, disempowers and infantilizes residents. It is an insufficient labour that violates the legitimate client-centred care that takes up the concerns and interests of the care recipients (Capri and Swartz, 2018; Johnson and Bagatell, 2017). Examples from institutional ethnography literature suggest front-line workers can negotiate these circuits using selfgoverning strategies that benefit them (e.g. Griffith and Smith, 2014); however, we argue that by participating in these circuits, habilitation technicians cast aside their moral obligations and perpetuate limitations to their own self-governance.

Broadly, this study addresses the following questions: (1) How are systems-level regulations (i.e. federal and state mandates) interpreted and implemented in an ICF/IID by staff? (2) To what extent do the habilitation technicians comply or resist institutional regulations/oversight? and (3) What do habilitation technicians think about their status and associated responsibilities within the ICF/IID? By exploring these questions, we aim to extend Bélanger and Edwards's (2013) notion of structurally defined bilateral employment relations by highlighting the nexus of tensions between management and labour. More specifically, we emphasize employment relations are mediated through regulatory frameworks and are continually negotiated by management, key front-line workers, and 
consumers. These negotiations can impact appropriate and inappropriate institutional practices that directly affect the care of adults with ID in ICFs/IID.

\section{Institutional ethnography: Theoretical framework and methodology}

Institutional ethnography (Smith, 1987, 2005) is a critical theory and methodology that directs the researcher's attention to the ways work regimes are linked to and influence the institutional processes that structure what people do every day (Bélanger and Edwards, 2013; Prodinger and Turner, 2013). Institutional ethnography begins with observing the range of experiences of daily life. In doing so, the researcher can identify the social practices or specific events from which a discourse may be explored (DeVault and McCoy, 2001). Specific emphasis is placed on 'work' - the paid and unpaid activities of the individuals and groups under investigation. Work is understood as being nested in discourses and attending to those discourses reveals the unacknowledged or unrecognizable work that people perform and how that work shapes and is being shaped through institutional practices.

Smith (2005) refers to institutional practices as the textually mediated managers (e.g. words, sounds, images) that are 'set into material form of some kind from which they can be read, seen, heard, watched' (Smith, 2005: 66). Specific to this study, the management of daily operations and plans of care for residents and habilitation technicians in an ICF/ IID are determined by a complex hierarchy of regulatory texts and mandates established by several local, state, and federal agencies. These texts generate institutional circuits (a broad term under which accountability circuits fall) that directly align habilitation technicians to the objectives and practices valued by the ICF/IID (DeVault et al., 2014). That is, textual hierarchies form the conduit through which circuits of accountability emerge.

Fundamental to institutional ethnography is an ontology that views social relations as the synchronization of the everyday (Campbell and Gregor, 2004; Smith, 1987, 2005), orienting the researcher to consider the systems-level mediators and the social and environmental forces that influence daily activities. Additionally, institutional ethnography offers a social theory and critical lens from which to discern how front-line workers come to make decisions, intentionally and subliminally. Those who engage institutional ethnography as a methodology view research participants as the experts in their own experience, but observe that participants may not necessarily see the more distant sites of coordination that shape their experiences (Smith, 1987, 2005); thus, analysing and communicating about that extra-local coordination is, in fact, the primary task of the institutional ethnographer (Smith, 2005).

\section{Research site and participants}

This study was completed in an ICF/IID, the Community Centre for Developmental Disabilities (CCDD), a residential facility located in the Southeastern United States. The CCDD provides state-funded programming, day and respite care, and educational services to 400 children and adults with ID. Hope House, the primary residence for the participants of this study, is one of the oldest residences at the CCDD. Hope House is 
home to five men and five women with profound ID and 22 staff members. To recruit staff and residents for participation in the study, the first author contacted the director of therapy services at the CCDD to discuss the aims and conditions of participation in a dissertation study. A formal meeting was convened, and a proposal for research activities was submitted to the CCDD human rights committee. Upon approval, the first author visited three residential homes affiliated with the CCDD. She met with house managers, staff including habilitation technicians, and residents and outlined the details of participation. Staff and residents of Hope House were the most responsive and agreeable to participate in the study. Staff who enrolled in the study included the director of therapy services (Cynthia), the house manager (Mary Ann), the first shift supervisor (Elijah), and five habilitation technicians (Heather, Margaret, Kena, Niecey, and Ann).

Administrators and managers at the CCDD were typically college educated, middleaged, and Caucasian. House managers, shift supervisors, and habilitation technicians typically had some college education (associate degree or less), were female, under 40 years of age, and primarily African American. These positions were also comparatively low-paying (less than US $\$ 30,000$ annual income) and considered relatively unskilled. In the United States, there is overrepresentation of minority groups in lower-ranked service positions; therefore, we emphasize these demographics as they are representative of the front-line workforce in ICFs/IID (National Direct Service Workforce Resource Center et al., 2008) and how notions of minority status, power, and voice may enter into the social relations of work in Hope House (Behtoui et al., 2017).

\section{Consent procedures}

All participants submitted verbal and written consent to participate. This included consent to the audio-recording of informal conversations and formal interviews by the first author. Names used throughout this manuscript are pseudonyms to protect the identities of the individuals and the facility involved. This study was approved by the Office of Human Research Ethics at the University of North Carolina at Chapel Hill and the human rights committee at the CCDD.

\section{Data collection methods}

Data were collected over a 14-week period by the first author. Participant observation, semi-structured interviews, informal conversations, and text work were the methods utilized to explore how habilitation technicians' self-governance and moral obligation to the residents were reorganized and aligned to the CCDD through circuits of accountability.

Participant observation. Observations occurred for six to 10 hours per day, four days per week to record the range of activities that occurred in Hope House over the course of a day. Staff were observed in congregate areas of Hope House (e.g. multipurpose room, dining room, patio), as well as in residents' bedrooms, the staff lounge, and on community outings. Activities included bathing, grooming, dressing, eating meals, watching television, sitting in the patio garden, going to dinner in restaurants, visiting a local park, and attending a weekend matinee. Additionally, Mary Ann and Cynthia were observed 
during meetings with habilitation technicians, administrative meetings, and care planning conferences with residents' guardians. Data recorded included key words and phrases, descriptions of people and the physical environment, interactions of the participants, traffic of people entering and exiting Hope House, location and times of day activities occurred, objects and documents used, and the first author's sensory experiences. Jottings also included which habilitation technicians organized activities and which habilitation technicians participated.

Interviews. Staff engaged in a hierarchy of roles and texts; therefore, to have a more nuanced understanding of how work regimes and circuits of accountability intersected front-line work, the first author interviewed participants occupying various roles. Interviews were conversational and aimed at eliciting narratives about participants' work responsibilities and daily activities, relations between residents, habilitation technicians, and management, and the texts important to their work. Other topics explored were habilitation technicians' history with caring for adults with ID, their documented and undocumented work tasks at Hope House, how daily activities were prioritized (decision-making), charting and paperwork, and administrative challenges.

Informal conversations about texts and how they informed habilitation technicians' work occurred during each observation. Informal group conversations also transpired during each observation. One formal group interview with eight habilitation technicians was completed. These interviews and conversations also centred on habilitation technicians' perceptions of their work and how regulatory texts were interpreted and enacted. These brief conversations were either included in the field notes or audio-recorded and transcribed. All formal interviews were 30 to 60 minutes in length and were recorded and transcribed verbatim.

Text work. Text work refers to identifying, reading, and linking everyday action to material and nonmaterial texts (Campbell and Gregor, 2004). Staff participants described three levels of texts that frame front-line service work at the CCDD: national, state-level, and local. National texts establish the requirements ICFs/IID must meet in order to participate in Centers for Medicare and Medicaid (CMS) programmes, as well as health and safety requirements, client protections, delineation of services, and surveyor guidelines (CMS, n.d.). State-level texts prescribe the licensing and regulating of ICFs/IID. These regulatory bodies are also responsible for surveying and evaluating programmatic and personnel matters in ICFs/IID. A considerable number of local texts outlined the roles and responsibilities of the habilitation technicians and provided the necessary documentation to hold them accountable to those responsibilities. The ways through which local texts are taken up and enacted by habilitation technicians will be further described below.

\section{Analysis}

Excerpts from field notes and interview transcripts were analysed using first and second cycle coding (Miles et al., 2014). First cycle coding included extracting and coding themes concerning staff work (e.g. daily support/caregiving with residents and administrative tasks) and staff relationships (e.g. habilitation technician relationships with 
residents, with each other, and with supervisors and directors). During the second cycle, data were coded for the policies and forms of documentation habilitation technicians identified as critical to their work. Data were constructed into narratives through an iterative and reflexive process (Srivastava and Hopwood, 2009). The first author presented the narratives to the participants, as well as experts in institutional ethnography and qualitative research methods to establish confirmability. The data were revisited and more focused connections between habilitation technicians' responsibilities and selfgovernance, and their immediate alignment to institutional objectives were developed. Analyses revealed a paradox in which self-governance through accountability circuits shifted responsibility from the organization level to habilitation technicians, while simultaneously negating professional judgement and moral care.

\section{Negotiating moral care, self-governance, and accountability}

The following sections describe the impact circuits of accountability impose on moral care and self-governance in front-line work for five habilitation technicians and the first shift supervisor at Hope House.

\section{'Keeping tabs on us': Aligning compliance and accountability}

Habilitation technicians documented on several forms evidenced of individualized training for all residents. These forms were used to provide the care team (i.e. house manager, psychologist, physical therapist, occupational therapist, speech language pathologist, nurse, social worker, and nutritionist) with data to determine whether and/or when amendments to habilitation training plans were required. Habilitation technicians indicated the residents' medical charts were the primary texts where information regarding activities and habilitation goals were maintained. Included in each resident's chart was the individual habilitation plan (IHP), meal plan, behavioural support plan, behavioural management checklist, 'body check' form, resident communication checklist, socialization and leisure activities form, staff communication log, and the electronic medical record log. Also included in each resident's chart was a daily schedule noting times of day activities were to occur.

Habilitation technicians completed forms in the residents' charts and the electronic medical record four to five times throughout their shift - upon arrival, during break times, and at the end of their shift. In some instances, the same information (e.g. resident positioning, toileting, behavioural management) was recorded in multiple places. When asked about documentation procedures Elijah responded:

I mean, it's so much paperwork. It's a lot. We have rules that we need to follow according to the centre, but we do what we need to do, you know. We have to follow the programming, but we do it in our own way.

Kena added:

I really don't know why we have to do things this way. I don't think they look at all of this, it's just a way of keeping tabs on us. Like they just giving us <expletive $>$ to do. I don't know, 
maybe state [referring to state ICF/IID surveyors] looks at it or something. We double and triple document. All these forms, all this stuff we constantly have to write down. We should be able to just put it in the chart or on the computer. What's the point of doing both?

Compliance came into conflict with what habilitation technicians viewed as their actual duties to the residents. More specifically, they believed documentation procedures were not aligned to beliefs associated with moral care and did not target activities that were most important to residents. Niecey affirmed, 'You can't come in here thinking about rules. You have to think about this like you're taking care of family'. Caring for residents as family was the model for doing 'programming ... in our own way'.

Habilitation technicians also discussed how their experiential knowledge was or was not considered in the day-to-day operations of Hope House by management. Margaret explained, 'They [CCDD administrators] act like they know, but they don't even know what we really do you know; but they decide what we need to write. It's too much. We don't even have time for this'. Margaret's statement emphasized the disconnect between institutional regulation and forms of care provided on the front line. Additionally, this statement underscores the lack of consideration for habilitation technicians' thoughts concerning compliance procedures. Elijah confirmed, 'I know we have to do it, but it just seems like a lot. It could be more streamlined, but they don't listen to us. Not even me'. Employee silence is structural - constraints are imposed by the institution through management, who may focus on the operational concerns of Hope House rather than issues fundamental to the care of residents and the morale of staff. This process requires powersharing. Although habilitation technicians can be brought into decision-making processes peripherally through documentation (i.e. charting evidence considered in IHP meetings), they may choose not to share information intentionally because they feel their contributions are not valued. This may also be confounded by race, as occupying both a minority status and lower occupational rank can distance habilitation technicians from positions of power.

All documentation was reviewed by each shift manager, the house manager Mary Ann, and the director of habilitation, Cynthia. Mary Ann utilized the data to provide a comprehensive report to the care team during residents' annual IHP care conference. Specifically, she noted whether residents met or did not meet habilitation goals as outlined in the IHP, if frequencies of challenging behaviours increased or decreased, changes in medical status, and changes in levels of care. Cynthia used their documentation to justify maintaining or updating residents' behavioural management and socialization plans and their habilitation training programmes. It is important to note that habilitation technicians were not directly involved in the care planning for the residents. They were not invited to attend care conferences or offered methods for amending habilitation goals. Decisions made by the care team were abstractly applied to the habilitation technicians' daily tasks. This directly impacted, and arguably undermined, habilitation technicians' self-governance.

The aforementioned texts produced material documents and technologies that kept habilitation technicians in compliance with the CCDD, which then allowed the CCDD to be in compliance with state and federal regulatory agencies. However, analyses further revealed that these texts did not account for the work that is most important to 
habilitation technicians such as ensuring residents were able to live their lives according to their own interests and preferences, celebrating special moments and events (e.g. birthdays and national holidays), and building meaningful relationships. These represent the elements of daily living habilitation technicians felt obligated to address and advocate for on behalf of the residents. The following section presents narratives on how habilitation technicians leveraged their self-governance by creating experiences to enhance residents' quality of life.

\section{'Lives like us': Advocacy and normalizing extraordinary moments as acts of resistance}

Juxtaposed with the institutional demands on the habilitation technicians are their personal commitments to the residents. Habilitation technicians highlighted advocacy as a critical aspect of their work. One habilitation technician, Margaret, shared what she considered to be important responsibilities:

We are supposed to be advocates for the clients. Definitely advocate first! Helping them do the things they want to and putting it in the plan. We do the medical appointments with them too. We go to parks and restaurants and try to do stuff around here [Hope House]. More than anything, we're supposed to make sure that their goals are run . . . whatever the goal is, that's what they're supposed to do . . . and you know we have to do their personal care stuff. We run their programming and make sure we cover the checklists.

It is interesting to note that Margaret's first stated responsibility is to be an advocate for residents. Margaret elaborated that advocacy included honouring residents' preferences, ensuring those preferences were considered for inclusion in their habilitation plan, allowing residents to experience typical activities people in mainstream communities enjoy, as well as providing opportunities to develop meaningful relationships with staff and other residents. Yet, after she first mentioned advocacy, she did not refer to it again. Instead, she listed the responsibilities outlined in the official personnel texts of the CCDD. In other words, Margaret discussed the tasks most valued by the institution as important aspects of her work.

When asked further about how habilitation technicians commit to advocacy, Margaret added:

I try to advocate for them because if I see stuff that's not right for the client, I will address it with the manager or the supervisor. And they [the supervisors] have to take action from there. You need to do the best job that you can possibly do. You should want the clients' home to look nice and clean for when visitors come in. You should want the clients to look nice so when people come in and see the clients and stuff they will say, 'oh that's, wow, that's really nice'. We do things for them. The clients are well maintained, dressed, and they seem like they are happy. Their home is beautiful, the clients live in a beautiful environment, and stuff like that.

Providing residents with a clean home and nice attire were viewed as essential elements of 'normal' living. The habilitation technicians' views of normalcy were measured 
against their own experiences (e.g. having a well-maintained home, dressing in nice clothing, enjoying community events, and celebrating special days); however, normalcy, as experienced by the residents, was constructed through the texts governing work at the CCDD. These texts emphasize safety and prevention, treatment, and rehabilitation rather than enhancing the experience and quality of life of residents. Therefore, in order to bring meaning to the everyday, habilitation technicians provided extraordinary experiences that go beyond the centre's basic operational standards while simultaneously adhering to the centre's expectations.

The following anecdote from a conversation with Elijah, first shift supervisor, illustrated the importance of bringing meaning to the lives of residents as part of front-line work:

We treat our clients like family, because that's what's right. Some of them don't even have family. Like Kevin. He came to us from the foster care system. Supposedly his mom died and his dad couldn't take care of him, but you know how it is with foster care. He had been abused and everything. So really, this is the first place he's been where he's really being taken care of. We make sure his birthdays are really special . . . We'll have a barbecue and buy him new movies. Sometimes we go overboard. Like at Christmas time, we really do it up. You can tell he feels bad because he sees everybody else's family coming and visiting. No one comes to visit him. Not even his guardian.

This anecdote described the importance of taking up the concerns and well-being of residents beyond providing basic needs. Habilitation technicians valued their relationships with the residents and were committed to care for them not as clients, but as family, even when it required extra work and spending personal funds. The commitment to care for residents in this way was not accounted for within the texts guiding their daily responsibilities; however, habilitation technicians sought to make these experiences part of the operational fabric of the CCDD.

Throughout the study, habilitation technicians spoke about how they created extraordinary experiences for residents. Elijah, Ann, and Heather shared reasons why they provided care beyond what is prescribed for the residents:

Elijah: We reject labels. It doesn't matter what their disability is. We want them to have lives like us . . . we try to make life seem as what society sees as normal as possible for them. Like we throw them barbeques. We throw them the big birthday parties, Halloween parties, Christmas parties. We do the whole nine yards!

Ann: We have to do for them. This is their home, not ours.

Heather: Yes! We want them to have normal lives just like us.

The habilitation technicians did not define the residents by their level of ID. They did not consciously allow the classification as 'severe/profound' to colour their interactions or decisions to engage them in certain activities. It was clear that the habilitation technicians incorporated the residents into their own interpretations of living a 'good life' based on their personal experiences, hopes, and expectations. They valued the residents as people and wanted them to be able to have the same 'normal' experiences as other 
adults their age; yet Ann said, 'this is their home not ours'. This implies that habilitation technicians can envision caring for residents in their actual homes, but they do not quite feel as 'at home' at the CCDD. Since holiday parties, barbeques, and other social functions only occurred for special occasions, they became extraordinary rather than ordinary; and because these extraordinary occurrences were not included in the institution's circuit of accountability, they were not always well received by administrators or the care team. These acts of informal resistance rejected the notion that adults with ID could not experience and enjoy these taken-for-granted activities and that these experiences should be included in the ordinary accepted practices of Hope House.

Habilitation technicians' efforts to create these experiences for residents were criticized by administrators at the CCDD. For example, Cynthia, a psychologist and director of therapy services, described the habilitation technicians as being unaware of residents' abilities to value or understand their need to celebrate birthdays, religious holidays, and other national observances due to their level of ID. She stated:

They [habilitation technicians] overestimate the residents' abilities . . . what they understand . . . I know they think they're really high level and can do more than they actually are able to ... They all function in the profound range.

Cynthia's counternarrative revealed the belief that habilitation technicians may not realize or acknowledge that they were providing experiences that the residents may not fully comprehend or even value. This counternarrative also brought to light the assumption that adults with ID cannot experience these activities in the same ways as non-disabled individuals; however, the habilitation technicians were compelled to ensure special events/occasions were deemed appropriate and feasible occurrences at the CCDD.

Literature consistently shows that feasibility in direct care or front-line work is contested (Bélanger and Edwards, 2013; Bigby et al., 2009; Lopez, 2010), as regulatory decisions are made by individuals who do not participate in direct care. At the CCDD, habilitative training and daily life planning are determined by a care team who utilized abstract knowledge, rather than deferring to the knowledge of those directly involved with residents on a day-to-day basis. Habilitation technicians reported that their work often was unacknowledged in the planning for and care of residents. The following scene from a fieldnote illustrates the disconnect habilitation technicians identified between themselves as knowledgeable self-governed advocates and those who represent and reinforce the regulatory system in which they work:

Four habilitation technicians (Heather, Ann, Niecey, and Kena) were sitting outside on the patio while residents were in their rooms in bed for afternoon naps. I sat around the picnic table with Ann and Heather; Kena and Niecey rocked in chairs alongside the patio wall beneath the trees. Kena said, 'You know what? Those people down the hill [pointing towards the CCDD administration building] have no idea about dealing with our adults (referring to the residents).' 'What do you mean?' I asked. She responded, 'We are the ones working with them. We work with them all day every day, but they try to tell us what to do. That shit is crazy don't you think?' Niecey added, 'The ones across the street (referring to CCDD administrators) have always made the decisions about what we do.' I further probed, 'How do you all provide your input?' Ann turned toward me with surprise, 'Input?' Her question was followed by Kena 
yelling, '<expletive>? Input?' Heather sat quietly but shook her head. I clarified, 'So are you saying you do not provide input?' Niecey explained, 'We have to tell Mary Ann (the house manager) what we think should happen and then she will relay it to everyone else in the meeting; but we're never asked to attend a meeting to give input directly. It's so ridiculous. We work with these folks eight hours a day, but you're going to tell me how to do my job? $<$ expletive >.' Kena agreed, 'Right! Like, if you want us to use certain words to get them to do something, I know if they will work or not and not them. They come up here for two minutes. You know.' Niecey conceded, 'That's right! We're here for hours. Hours! That should matter, but it doesn't.'

Habilitation technicians saw themselves in many practical ways as the 'real' family members who were the experts on the residents, and yet they were not included in the decision-making, which invalidated their work and expertise. They acknowledged that they were powerless in their own self-governance because they were not invited to the 'care planning table'. They made exceptions for their house manager, Mary Ann, who communicated their concerns and suggestions to the care team; however, they recognized that this was passive participation. Schwarzkopf and Kiger (2012) confirmed that leadership and care planning often begins with middle and executive-level management, rather than the front line. The lack of interface between the care team and habilitation technicians may lead to the perpetuation of barriers limiting how they enhance residents' quality of life.

\section{Discussion}

Habilitation technicians are charged with providing quality personal care and habilitation training to adults with ID at the CCDD. To do so, they must decode and decipher the language of several policies coupled with the institutional texts that outline their daily job duties. These texts are informed by a convergence of work regimes that establish a complex hierarchy of regulations and procedures that are taken up and enacted differently based on one's status within their organizational hierarchy (Bélanger and Edwards, 2013). Habilitation technicians must adhere to and maintain regulatory standards by engaging in circuits of accountability. These circuits tie their work to institutional objectives through a system of documentation. That is, habilitation technicians are required to verify, both in material and electronic form, that specific tasks are completed every day. Analyses revealed that this documentation is a reflection of both horizontal accountability (demands for the habilitation technicians at the local level) and vertical accountability (demands for the CCDD at the state and national level). Equally important was their moral care to adults with ID; however, their commitment to improving residents' quality of life was not directly aligned, and sometimes conflicted with, these standards as determined by accountability circuits.

Grace et al. (2014) argued that front-line workers utilize a range of strategies to negotiate accountability circuits, while simultaneously attending to their own work needs. By virtue of participating in accountability circuits, front-line workers accept their participation as inevitable. Bélanger and Edwards (2013) also suggested that workers are able to harness power that allows them the ability to negotiate the relationships and forces 
coordinating work in order to produce particular outcomes. We argued that whereas habilitation technicians have accepted their participation in accountability circuits as inevitable, they do not possess the necessary power or professional leverage required to accrue sustainable benefits to themselves or the residents through their participation in these circuits. This limitation may be attributed not only to their occupational rank within the CCDD, but may be confounded by their minority status, which has been indicated in influencing voice and silence in the employment relationship.

In their study of minority workers, Behtoui et al. (2017) confirmed that workers from African, Asian, or Latin American backgrounds tended to be less convinced than others of a favourable voice climate even after controlling for occupational status. The authors also noted that occupational status/power position had a significant relationship to belief in voice climate. Donaghey et al. (2011) offered a comprehensive and multidimensional approach to understanding how employee silencing occurs - it is relational and shaped by management and subordinate employee strategies in furthering their respective concerns. Silence can be a product of distrust or a means of positioning oneself in the employer/employee power relationship. Work relationships are not equal but bend toward the group in positions of power and are in constant negotiation between conflict and cooperation (Subramanian and Suquet, 2018). This negotiation was noted in habilitation technicians particularly when advocating to establish extraordinary moments (e.g. birthday and holiday celebrations) as regular occurrences and prioritizing moral work over custodial care. Although habilitation technicians created experiences that were not prescribed as part of the residents' IHPs, their efforts to make these experiences an institutional practice had not yet been realized. Doing 'moral work' to bring normalcy and enhance quality of institutionalized living for residents had not been recognized as a sufficient measure of habilitation in the governing of ICFs/IID.

Skorupski (2010) argued that people make personal commitments to others based on a moral assessment of their actions. This assessment is reinforced by their own personal and social experiences, which then become embodied. Skorupski also argued that these commitments are inextricably tied to self-governance in that an individual's acts of selfgovernance must also reflect those commitments. They must 'assess whether they have sufficient reason to believe, or feel, or act-or whether they must investigate further before they have sufficient reason . . . to act [based on] their conclusions' (Skorupski, 2010: 159). The ability to act on those conclusions is influenced by a person's capacity to be self-determined. The analyses presented in this article challenge the idea that habilitation technicians have the power to act on their own conclusions. The extent to which habilitation technicians can fulfil their commitment to enhancing residents' quality of life is limited by procedures and checklists framed within the structural complexity of federal and state legislation (Smith, 2005). Habilitation technicians' work is systematically aligned to a regime that deems institutional life to consist of prevention, treatment, and habilitation, rather than building a sense of community and belonging through meaningful relationships and experiences. However, the institution is a dynamic system. It creates and recreates opportunities or marginalization through policies and the social encounters of its people (Bjerregaard and Jonasson, 2014). These are qualities that cannot be written into policy or driven by administrative abstractions. They must be instituted with sincere engagement with individuals with ID (Johnson et al., 2010). 
Habilitation technicians' alignment to these institutional regimes impacts their ability to significantly influence a legislative system that has not yet recognized the range of experiences that constitute quality life for institutionalized individuals with ID. Arguably, moral obligations and self-governance appear to be incompatible with accountability circuits. This is because circuits require habilitation technicians to compartmentalize their morality/moral obligations, which is essentially dehumanizing for them, and indirectly dehumanizing for the residents. Habilitation technicians harness the passion to provide the utmost care for the residents but none of the power, which makes them feel unvalued. As noted during their discussion on the perceived value of their position within the organization, their lack of participation in decision-making for direct care and the habilitation of residents not only undermines their moral obligation, it can contribute to job dissatisfaction (Gray and Muramatsu, 2013). This calls attention to the need for advocacy support in direct care and other front-line work (Brolan et al., 2012). We argue that this goes beyond support to valuing habilitation technicians as knowledgeable contributors. In many ways, habilitation technicians serve as the voice of the residents. Their exclusion from care planning ultimately affects how habilitation is prioritized and care implemented. Honouring habilitation technicians as integral, self-governing members of the care team brings to the fore and systematically aligns an institution's moral obligation to prioritize the quality of life of residents with ID to accountability circuits.

\section{Limitations and future considerations}

Determining an appropriate sample size for qualitative research has been a point of debate for some time. Experts have proposed sufficient samples range from 5 to 50 individuals and upwards of 60 or more interviews (Dworkin, 2012; Vasileiou et al., 2018), and noted the concept of 'information power' as a guide to achieving saturation (Malterud et al., 2016). The small sample of participants for the study may limit generalizations that can be applied to front-line workers who fit the demographics, work in settings that are characteristically institutional, and perform similar duties; however, the heterogeneity of roles represented in the sample allowed us to explore the range through which policies were interpreted and enacted at various points in the organizational hierarchy. Additionally, due to the specificity of the research setting, interpretation of the findings should not be applied beyond the scope of services at the CCDD or to other residential settings where adults with ID receive habilitative services.

This study emphasized the textual relations of front-line work in an ICF/IID and contributed a nuanced understanding of the convergence of work setting, regulatory frameworks, organizational hierarchy, and occupational status and its impact on moral care. Although institutional ethnography made visible the social relations that shaped moral care, it did not demonstrate the impact of non-textual mediators on labour processes; therefore, in conjunction with conventional ethnographic methods, scholars may address the following areas of inquiry that emerged in this study: the role of 'power proxies' in the employment relationship particularly when consumers of services are non-verbal and have a socio-political minority status; how studies of institutional settings move forward notions of voice climate and how racialization of work is perpetuated through textual 
hierarchies; and how acts of resistance function as tools of power to address the concerns of individuals who occupy subordinate positions.

\section{Conclusion}

In this article, we argue that habilitation technicians who perform front-line work in an ICF/IID must enact and negotiate various accountability circuits. These accountability circuits are products of a complex hierarchy of national and state legislative texts that outline standards of operation and care for institutionalized adults with ID. The net effect of this alignment negatively impacts habilitation technicians' ability to exercise selfgovernance and fulfil their moral obligations to residents to ensure an improved quality of life. This article also highlights the need to recognize and acknowledge how habilitation technicians are situated within these circuits. This is not because they demonstrate valuing people as people as novel; instead, they personify the move away from applying abstract ideas of what enhances quality of life to committing to understanding the nuances of engaging with individuals with ID. Findings from this study also have implications for management and implementation of direct care services in other settings with institutional qualities, and underscore the importance of moral obligation and selfgovernance to front-line work.

\section{Funding}

The authors received no financial support for the research, authorship, and/or publication of this article.

\section{ORCID iD}

Khalilah Robinson Johnson (iD https://orcid.org/0000-0003-4774-056X

\section{References}

Behtoui A, Boréus K, Neergaard A and Yazdanpanah S (2017) Speaking up, leaving or keeping silent: racialized employees in the Swedish elderly care sector. Work, Employment, and Society 31(6): 954-971.

Bélanger J and Edwards P (2013) The nature of front-line service work: distinctive features and continuity in the employment relationship. Work, Employment, and Society 27(3): 433-450.

Bigby C, Clement T, Mansell J and Beadle-Brown J (2009) 'It's pretty hard with our ones, they can't talk, the more able bodied can participate': staff attitudes about the applicability of disability policies to people with severe and profound intellectual disabilities. Journal of Intellectual Disability Research 53(4): 363-376.

Bjerregaard T and Jonasson C (2014) Managing unstable institutional contradictions: the work of becoming. Organization Studies 35(10): 1507-1536.

Braddock DL, Hemp RE, Tanis ES, Wu J and Haffer L (2017) State of the States in Intellectual and Developmental Disabilities, 11th edn. Washington, DC: American Association on Intellectual and Developmental Disabilities.

Brolan CE, Boyle FM, Dean JH, Gomez MT, Ware RS and Lennox NG (2012) Health advocacy: a vital step in attaining human rights for adults with intellectual disability. Journal of Intellectual Disability Research 56(11): 1087-1097. 
Campbell M and Gregor F (2004) Mapping Social Relations: A Primer in Doing Institutional Ethnography. Walnut Creek, CA: AltaMira Press.

Capri C and Swartz L (2018) 'We are actually, after all, just children': caring societies and South African infantilization of adults with intellectual disability. Disability and Society 33(2): $285-308$.

Centers for Medicare and Medicaid Services (CMS) (n.d.) State operations manual: Chapter 1 - program background and responsibilities. Available at: https://www.cms.gov/Regulationsand-Guidance/Guidance/Manuals/Downloads/som107c01.pdf (accessed 15 November 2018).

DeVault ML and McCoy L (2001) Institutional ethnography: using interviews to investigate ruling relations. In: Gubrium JF and Holstein JA (eds) Handbook of Interview Research: Context and Methods. Thousand Oaks, CA: SAGE, 751-776.

DeVault M, Venkatesh M and Ridzi F (2014) 'Let's be friends': working within an accountability circuit. In: Griffith A and Smith D (eds) Under New Public Management: Institutional Ethnographies of Changing Front-Line Work. Toronto, ON, Canada: University of Toronto Press, 177-198.

Donaghey J, Cullinane N, Dundon T and Wilkinson A (2011) Reconceptualising employee silence: problems and prognosis. Work, Employment, and Society 25(1): 51-67.

Dworkin SL (2012) Sample size policy for qualitative studies using in-depth interviews. Archives of Sexual Behavior 41(6): 1319-1320.

Grace L, Zurawski C and Sinding C (2014) A workshop dialogue: institutional circuits and front-line work of self-governance. In: Griffith A and Smith D (eds) Under New Public Management: Institutional Ethnographies of Changing Front-Line Work. Toronto, ON, Canada: University of Toronto Press, 253-293.

Gray J and Muramatsu N (2013) When the job has lost its appeal: intentions to quit among direct care workers. Journal of Intellectual and Developmental Disability 38(2): 124-133.

Griffith A and Smith D (2014) Under New Public Management: Institutional Ethnographies of Changing Front-Line Work. Toronto, ON, Canada: University of Toronto Press.

Johnson K and Bagatell N (2017) Beyond custodial care: mediating choice and participation for adults with intellectual disabilities. Journal of Occupational Science 24(4): 546-560.

Johnson K, Walmsley J and Wolfe M (2010) People with Intellectual Disabilities: Towards a Good Life? Bristol: The Policy Press.

Lopez SH (2010) Workers, managers, and customers: triangles of power in work communities. Work and Occupation 37(3): 251-271.

Malterud K, Siersma VD and Guassora AD (2016) Sample size in qualitative interview studies: guided by information power. Qualitative Health Research 26(13): 1753-1760.

Miles M, Huberman A and Saldaña J (2014) Qualitative Data Analysis: A Methods Sourcebook, 3rd edn. Thousand Oaks, CA: SAGE.

National Direct Service Workforce Resource Center, Hewitt A, Larson S, Edelstein S, Seavey D, Hodge MA, et al. (2008) A synthesis of direct service workforce demographics and challenges across intellectual/developmental disabilities, aging, physical disabilities, and behavioral health. Available at: https://nadsp.org/wp-content/uploads/2016/08/Cross-DisabilitySyn thesisWhitePaperFinal.pdf (accessed 15 November 2018).

Nielsen K (2012) A Disability History of the United States. Boston, MA: Beacon Press.

Prodinger B and Turner S (2013) Using institutional ethnography to explore how social politics infiltrate everyday life. Journal of Occupational Science 20(4): 357-369.

Schwarzkopf R and Kiger A (2012) Taking charge: front-line nurse leadership development. Journal of Continuing Education in Nursing 43(4): 154-159. 
Skorupski J (2010) Moral obligation, blame, and self-governance. Social Philosophy and Policy 27(2): 158-180.

Smith D (1987) The Everyday World as Problematic: A Feminist Sociology. Toronto, ON, Canada: University of Toronto Press.

Smith D (2005) Institutional Ethnography as Practice. Oxford: Rowman \& Littlefield.

Sørensen E and Triantafillou P (2016) The politics of self-governance: an introduction. In: Sørensen E and Triantafillou P (eds) The Politics of Self-Governance. Farnham: Routledge, 1-22.

Srivastava P and Hopwood N (2009) A practical iterative framework for qualitative data analysis. International Journal of Qualitative Methods 8(1): 76-84.

Subramanian D and Suquet J (2018) Unpacking the service triangle: arranging power relations between frontline occupations. Work and Occupations 45(1): 38-81.

Vasileiou K, Barnett J, Thorpe S and Young T (2018) Characterising and justifying sample size sufficiency in interview-based studies: systematic analysis of qualitative health research over a 15-year period. BMC Medical Research Methodology 18(1): 148.

Wagner K (2014) Regulating the alternative: certifying organic farming on Vancouver Island, British Columbia. In: Smith D and Turner S (eds) Incorporating Texts into Institutional Ethnographies. Toronto, ON, Canada: University of Toronto Press, 41-63.

Wehmeyer M (2013) The Story of Intellectual Disability: An Evolution of Meaning, Understanding, and Public Perception. Baltimore, MD: Paul H. Brookes Publishing.

Khalilah Robinson Johnson is an Assistant Professor in the Division of Occupational Science and Occupational Therapy at the University of North Carolina at Chapel Hill. Her research foci include issues in policy and practice in institutional habilitation settings, community engagement and integration of individuals with intellectual and developmental disabilities, and transition and employment of young adults with intellectual disability. Dr Johnson also serves as a senior reviewer and occupational therapy clinical consultant for Elsevier Inc.

Nancy Bagatell is an Associate Professor and Director of the Division of Occupational Science and Occupational Therapy at the University of North Carolina at Chapel Hill. Broadly, her research interests include the transition needs of youth with developmental disabilities, the daily life experiences of adults with autism spectrum disorders and cerebral palsy and their caregivers, and therapeutic intervention to increase community living and participation in marginalized populations.

Date submitted December 2018

Date accepted July 2019 